\title{
Socially critical
}

decisions towards

low status groups:

the role of meritocracy

Rui Costa-Lopes

Ana Filipa Madeira

Mariana Pires de Miranda

Wilson Moreira 
We make trivial decisions everyday but, every once in a while, we face decisions that have a deep impact on others, as they may imply serious harm or the unequal distribution of relevant material or symbolic resources. These socially critical decisions (SCD) constitute the core of this chapter. Its main goal is to describe the literature on these scd and present empirical research testing how the contextual salience of a meritocratic norm impacts on these decisions towards low status group members.

The first part of this chapter will describe the existing research on SCD within asymmetric social relations that has mostly focused on different examples, such as "shoot vs. not-shoot" police decisions as a function of different ethnic target groups, medical decisions, moral dilemmas and legal decisions. A consistent result across these different decisional contexts (though with some caveats) indicates that low status group members (e.g. blacks, gypsies, the homeless) are targeted with more unfavorable decisions, therefore suggesting an inequality in treatment that may be undermining the full scale inclusion of these group members.

We describe how this research has been more focused on showing this group-based discrimination in SCD than in explaining it. Importantly, a significant factor that has been consistently shown to impact on group-based distinctions has been neglected by SCD research: the salience of a meritocratic norm. Although seen as an important social norm that regulates society, descriptive meritocracy - i.e. the belief that people are rewarded based on their efforts - is nonetheless associated with intolerance and dislike of low status group members and may therefore be logically associated with more unfavourable decisions towards low status groups. This lay explanation of discrimination may legitimise the maintenance of inequality and limit actions towards inclusion. In the second part of this chapter, we will present the rationale for such hypothesis and present our own research developed around this idea. We end the chapter with a succinct discussion on how this bias in SCD hinders a full integration of low status group members in society.

SHOOT VS. NOT SHOOT DECISIONS TOWARDS LOW STATUS GROUP MEMBERS

Police shootings are a paradigmatic example of a situation where individuals are forced to make socially critical decisions that may carry very serious 
consequences. Police officers face a challenging situation when arriving at a dangerous scene: there may be several individuals, with some of them being armed and others not. In a fraction of a second, the police officer needs to make a shoot vs. not shoot decision. Not to shoot an armed individual may result in the police officer getting shot, shooting an unarmed individual may lead to a tragic loss of innocent lives. Moreover, these wrong decisions may lead to major social unrest.

In New York, 1999, Amadou Diallo, a 22 year old African immigrant was shot and killed by the police when he tried to reach for his pocket to show some ID and the police mistakenly assumed he was reaching for a gun. Several similar incidents with African Americans have occurred since, namely the shooting of Sean Bell in 2006 and the shooting of Trayvon Martin in 2012. In all these incidents, public opinion was focused on one question in particular: would the police officers have made the same decision if the suspect had been white, or even just non-black?

This was the question that led Joshua Correll and his colleagues at the University of Colorado at Boulder to set up a research programme that would help provide some answers by recreating in a controlled environment, as realistically as possible, the experience that police officers go through when they are expected to make these decisions. Accordingly, Correll developed a video game simulation in which White or Black targets appeared in different poses and against different backgrounds during several trials of the task, either holding a gun or a neutral object (e.g. mobile phone). Correll and colleagues first used this computer game in a study with university students as participant colleagues (Correll et al. 2002). Results yield a pattern of shooter bias, where participants decide to shoot Black more quickly and more frequently than White targets. Additionally, participants, on average, required more time to make the decision not to shoot an unarmed suspect when the suspect was black than white.

After some years, the same researchers decided to assess the presence of such shooter bias within the police officer population of a major us city in the same state as the first study. Using the community population of the same geographical area as a comparison sample, police officers went through the same computer simulation and results showed that both police officers and community samples exhibited robust racial bias in terms of speed, i.e. participants were quicker to make the decision to shoot black suspects than white suspects. Notably, however, police officers did not show the same shooter 
bias effect in terms of the final decision. That is, although community members set the shooting decision criterion lower for Black targets (compared to White suspects), police officers outperformed them by expressing no such bias in the decision (Correll et al. 2007). According to the authors, results seem to indicate that the training that police officers go through may not affect the speed with which stereotype-incongruent targets are processed, but that it does affect the ultimate decision. This result is consistent with the hypothesis that the shooter bias effect is partially explained by the stereotypical associations that the participants have of the targets. In other words, people take less time in making a decision that is consistent with Black and White stereotyping and more time in making a decision that is inconsistent. Implicit prejudice (i.e. negative stereotypes) leads to more unfavourable decisions towards Blacks.

The research line developed by Correll and colleagues is consistent with (and indirectly supported by) research from other us-based social psychology colleagues. For example, Payne (2001) developed a paradigm in which he was able to demonstrate that, when guessing the real content hidden in blurred images, participants are quicker to distinguish weapons from tools when they have been previously primed with pictures of Black faces, compared to White faces. Another (more indirect) example comes from research by Eberhardt and colleagues (Eberhardt et al. 2004), showing that people have a stronger tendency to turn their attention to Black faces, than to White faces, when they have been primed with the concept of crime.

\section{SOCIALLY CRITICAL DECISIONS TOWARDS LOW STATUS GROUP MEMBERS IN MORAL DILEMMAS}

The classic example of socially critical decisions comes from the study of moral dilemmas, although in this case, these are often based on artificial situations created to illustrate fundamental ideas. Nonetheless, these fundamental ideas often resonate with real examples from everyday life. When we decide, for example, if we support a war that will most likely kill hundreds of soldiers and civilians for the sake of a more just society; or when a fireman has to decide, during a fire, whether he goes left, to save two elderly people, or right, to save a baby.

But how do we decide in these situations? Do we maximise the number of people we save? In theory, moral rules are rigid and absolute. The Bible's Ten 
Commandments include unequivocal exclusions such as "Thou shalt not kill" In real life, however, people are often puzzled about what is the right thing to do. Though it is not yet completely clear what drives people's decisions within these moral dilemmas, some consistent results have already been identified. A most relevant example for this chapter concerns decisions within moral dilemmas involving people from low status groups.

The classic example of a moral dilemma is the "trolley dilemma". This dilemma has several versions but the most common one is a version with a lever: "There is a runaway trolley barrelling down the railway tracks. Ahead, on the tracks, there are five people tied up and unable to move. The trolley is headed straight for them. You are standing some distance off in the train yard, next to a lever. If you pull this lever, the trolley will switch to a different set of tracks. However, you notice that there is one person tied up on the side track." Thus, you have two options, you either do nothing, which means the trolley will kill the five people on the main track, or you decide to pull the lever, which diverts the trolley to the side track, saving five people but killing one.

While there is no consensus on what the right decision is here, the two fundamental principles that are evoked by those making one decision or the other have been identified. A deontological principle states that the morality of an action lies in its intrinsic nature (Kant 1785 [1959]), which means that causing harm is always wrong, regardless of any positive consequences that may derive from that action. This principle is evoked by people who choose not to do anything. The utilitarian principle states that the morality of an action depends indeed on its consequences and that we should make the decision that maximises the well-being of the majority of people involved (Mill 1861 [1998]). This is the principle evoked by people who choose to kill one in order to save five, as the number of lives saved by that decision is larger than the number of sacrificed victims. Hundreds of thousands of people have responded to the trolley dilemma and its lever version. And even though there is no consensus, the majority of individuals favour the utilitarian principle that you should kill one to save many (Cushman, Young and Hauser 2006; Greene et al. 2001).

Recently, Cikara and colleagues (Cikara et al. 2010) brought the status dimension to trolley dilemmas involving victims and other individuals differing in terms of social status. Cikara and colleagues presented several trolley dilemma scenarios to participants, manipulating the social status 
of the five people on the main track and the victim on the side track by presenting pictures in different scenarios. ${ }^{1}$ Results showed that participants see the utilitarian decision - i. e. the decision to sacrifice the victim on the side track to save the five people on the main track - as more favourable when the victim belongs to a low-competence group and that the scenario in which the sacrifice of the victim was seen as more acceptable was the one involving a victim belonging to a group seen as having both low-competence and low warmth (e.g. the homeless or drug addicts). To our knowledge, no other study has manipulated the victims' status within moral dilemmas, instead, the research has been more focused on distinguishing how participants from upper- and lower-classes respond to the dilemmas (Côté, Piff and Willer 2013).

\section{SOCIALLY CRITICAL DECISIONS TOWARDS}

\section{LOW STATUS GROUP MEMBERS IN THE MEDICAL CONTEXT}

Research on medical decisions is considerably more developed than the previous two research areas. Consistent with other decision making domains, health care providers demonstrate implicit biases suggesting the existence of discriminatory attitudes and decisions towards low status groups, such as Blacks (Blair et al. 2013; Cooper et al. 2012; Green et al. 2007; Haider et al. 2011, 2015a, 2015b; Hausmann et al. 2015; Sabin et al. 2009; Schaa et al. 2015; Stepanikova 2012) and Latinos (Blair et al. 2013; Stepanikova 2012).

So why should the level of bias of a particular health provider be of concern during medical decision making? Evidence from four systematic reviews suggests a significant positive relationship between level of implicit bias and lower quality of care (Hall et al. 2015; Paradies, Truong, and Priest 2014; FitzGerald and Hurst 2017; Dehon et al. 2017). This lower quality of care manifests itself in more negative patient-provider interactions but also in clinical decisions. Indeed, a large body of research found empirical evidence of implicit bias influencing clinical decision making towards low status

1 A short note here to define social status in this context. Fiske and colleagues (Fiske et al. 2002) posited that group stereotypes are defined in terms of two fundamental dimensions: competence and warmth. A person belongs to a low status group when that group is perceived as being low in competence or warmth, and naturally the lowest status is attributed to people who are seen as both incompetent and cold. 
groups (Bogart et al. 2001; Burgess et al. 2008; Di Caccavo, Fazal-Short and Moss 2000; Drwecki 2011; Ponterotto, Potere and Johansen 2002; Green et al. 2007; Hirsh, Jensen and Robinson 2010; Stepanikova 2012; Sabin, Rivara and Greenwald 2008; Schulman et al. 1999; Thamer et al. 2001). For example, Schulman and colleagues (1999) found that physicians were less likely to refer Black women for cardiac catheterisation, even after controlling for symptoms, i. e. the physicians' estimates of the probability of coronary disease and clinical characteristics. Also two studies on treatment recommendations found that providers with greater implicit racial bias are less likely to recommend thrombolysis treatment when presented with clinical vignettes presenting patients with chest pain symptoms, and are less likely to prescribe postsurgical pain medication for a low status patient (Black) than a high status patient (White) (Green et al. 2007).

Several studies have shown how the salience of target status group indirectly activates racial stereotypes during clinical decision making. For example, studies using racial primes found physicians' medical decisions being influenced when subliminally exposed to Black and Hispanic stimuli (Stepanikova 2012), specifically, when primed with stereotypes related to African Americans, participants tended to rate a hypothetical patient more negatively. Another study found that physicians rated Black patients as less likely than Whites to comply with medical advice or participate in cardiac rehabilitation if prescribed, although these differences were of only borderline statistical significance (Van Ryn et al. 2006). Moskowitz and colleagues (2012) found that physicians had lower trust in non-White, compared with White, patients.

Furthermore, the salience of target status group seems to indirectly affect individual's evaluations and judgements during socially critical decision making. For example, in a study intended to examine medical students' willingness to prescribe antiretroviral pre-exposure prophylaxis (PrEP) to a White vs Black patient, participants judged the Black patient to be more likely to increase his rate of unprotected sex if prescribed PrEP, which, in turn, was associated with reduced willingness to prescribe PrEP to the Black patient (Calabrese et al. 2014). A similar indirect effect was not found for the white patient. This result is consistent with research on stereotype activation in clinical judgement and decision making (Hirsh, Jensen and Robinson 2010; Van Ryn et al. 2006), suggesting that physicians often associate a racial category with racial stereotypes and use them as decision making heuristics 
leading to corresponding behaviour. Moreover, it has been shown how implicit stereotyping may affect diagnosis and treatment without conscious knowledge of its influence, or may even unduly influence diagnosis and treatment (Bean et al. 2014; Dovidio and Fiske 2012; Moskowitz, Stone, and Childs 2012).

More recently, studies have shown how cognitive stressors (e.g. time pressure, cognitive load) may promote reliance on stereotypes and racial bias during decision making (Burgess et al. 2014; Stepanikova 2012). For example, it was found that male physicians were using controlled processes to "correct" for racial stereotypes when they had the opportunity to do so (e.g. sufficient cognitive resources), but were influenced by racial stereotypes in their decision making when under cognitive busyness (Burgess et al. 2014).

\section{SOCIALLY CRITICAL DECISIONS TOWARDS \\ LOW STATUS GROUP MEMBERS IN THE LEGAL CONTEXT}

Research on decision making in the legal context is fairly developed too and it also yields results showing that low status group members are targeted with more unfavourable decisions. However, the dimension this research most focuses on is the one referring to racial categories, i.e. the research on legal decisions that informs about possible bias against low status group members is almost exclusively about more negative decisions towards different-race targets.

A recent Portuguese investigative journalism story (Henriques, 2017-08-19) has described that one in every 73 citizens of Lusophone Africa over 16 years old and living in Portugal is in prison, whereas for Portuguese citizens in the same age group the proportion is one to 736 . The same kind of results have come up throughout the years in different national investigations (Oliveira and Gomes 2014; Roldão 2016; Seabra and Santos 2006). However, this is clearly not an exclusive problem for Portugal. In the USA, for instance, $38 \%$ of the people in prison are Black, 21\% are Hispanic, whereas they represent $13 \%$ and $17 \%$ of the total population, respectively (Nellis 2016). As striking as these proportions are, they should be interpreted cautiously. Seabra and Santos (2006) have modulated scenarios within the Portuguese context in which the ratios of incarcerated population in function of the total group population account for confounding variables (such as the social structure of the groups), and even for distortions in the data (such as the non-inclusion 
of people with irregular status; the inclusion of foreigners who do not reside in the country, etc.). When taking into consideration the bigger picture, the difference between the likelihood of a migrant being in prison compared to a Portuguese citizen decreases but is, nonetheless, greater for the migrant group than for the Portuguese group in every scenario.

These differences were described and analysed in Faigman and colleagues' review in terms of the different stages of the criminal path, from (1) the Police encounter, moving to (2) the Charge and plea bargain, and (3) the Trial, and ending with (4) the sentencing (Faigman et al. 2012). The Police encounter phase is sufficiently discussed in the section on shoot vs. not shoot decisions.

To our knowledge, there are few studies that describe what happens in the phase in which prosecutors decide to charge or not to charge someone for a given crime. Furthermore, from the results of these studies, it is not possible to describe a consistent pattern, with analysis of justice data sets suggesting either some (Radelet and Pierce 1985) or no disparate decisions by prosecutors (Caravelis, Chiricos and Bales 2013). As such, studies that can isolate the effect of race or status in the charge and plea bargain phase are in need.

More attention has been given to the trial and sentencing phases, in regard to which we highlight three meta-analyses conducted in the context of mock trials. Mazzella and Feingold (1994) conducted a meta-analysis including 29 studies which revealed a non-significant effect of racial bias on either trial judgments or sentences, but with the defendant's race having an effect on sentences qualified by the type of crime.

On the other hand, a meta-analysis conducted by Sweeney and Haney (1992), including 14 studies, reported a small but significant racial bias in the sentencing phase, with White participants giving Black defendants longer sentences than White ones. To integrate these inconsistent findings, Mitchell and colleagues (Mitchell et al. 2005) conducted another meta-analysis exploring possible moderators of this racial bias effect. The authors defined racial bias specifically as "a juror's disparate treatment of a defendant from a racial out-group, when compared with a defendant of the juror's own-race, in verdict and sentencing decisions". As such, the authors aimed at extending this effect to an other-race context. Results unequivocally demonstrated the existence of a small but significant other-race racial bias in studies addressing juror decision making, which nonetheless, and in line with our argument, became more pronounced when White jurors evaluated Black defendants. 
Data coming from studies conducted in natural contexts is consistent with the prior evidence. At a national level, we highlight the analysis done by Oliveira and Gomes (2014), which demonstrates that foreigners are sentenced for longer periods of time than national citizens convicted of the same crimes. Graham and Lowery (2004) tried to experimentally isolate the effect of race in sentencing by natural groups in the legal system (police and probation officers). The authors demonstrated that when primed with content related to the Black group, the proposed sentence was harsher.

Another line of research still within the description of racial bias in SCD (within the legal area) has moved away from the analysis of racial category to focus specifically on the physical traits associated with Black characteristics (i. e. Afrocentric Features, such as darker skin or a wider nose). On a series of five studies using different laboratorial paradigms, Eberhardt et al. (2004) have shown that both lay participants and police officers associate stereotypicality with criminality.

Eberhardt and colleagues (2004) moved beyond the laboratory in their analysis and went through a large legal us database (Baldus et al. 1998) to select actual black murder defendants advancing to penalty. The aim was to test their hypothesis that the display of Afrocentric features would predict the likelihood of their conviction turning into a death sentence. In two studies with naïve participants, the authors proved that, even when controlling for a large set of covariates, the stereotypicality of Black defendants did predict the death sentence when the victim was White, but not when the victim was Black (Eberhardt et al. 2006).

Blair, Judd and Chapleau (2004) directly tested the effect of group race against Afrocentric features, and found evidence that the effect of Afrocentric features does prevail over the effects driven by group race. These results are still in line with the explanation of the differential treatment in terms of prejudice and, in particular, in terms of implicit prejudice (Faigman et al. 2012). Some evidence suggests that stereotypical information (e.g. Afrocentric features) is linked to perception (e.g. of criminality), regardless of individual explicit bias (Eberhardt et al. 2004). Similarly, but more directly linked to socially critical decisions in the legal context, Sommers and Ellesworth $(2000,2001)$ showed that, when the race dimension was made salient in the courtroom, discrimination did not occur; whereas when it was explicitly ignored, the bias in sentencing for Blacks and Whites emerged. Thus, overall, research does suggest the existence of more unfavourable decisions towards low status group members. 
THE ROLE OF MERITOCRACY ON SOCIALLY CRITICAL DECISIONS TOWARDS LOW STATUS GROUPS

The previous sections went through a large body of studies describing the existence of more unfavourable socially critical decisions towards low status group members in shoot vs. not shoot decisions, in moral dilemmas, in medical decisions, and in legal decisions. Research has been more focused on showing this group-based discrimination in SCD than in explaining it. Indeed, though a significant part of these studies explored the pivotal role played by implicit prejudice in the existence of this bias in decision making, no other variable that is usually predictive of biased attitudes and behaviours in intergroup asymmetrical contexts has been considered. Importantly, a significant factor that has been consistently shown to impact on group-based distinctions has been neglected by SCD research: the salience of a meritocratic norm.

Meritocracy is a social norm according to which social status and rewards depend, or should depend, on individual effort and hard work (Kluegel and Smith 1986). This distinction between "depend" and "should depend" is a fundamental one that applies to all social norms, namely the meritocratic norm: the distinction between prescriptive vs. descriptive norms.

Descriptive norms describe what typically happens in a society and derive from the way people normally act in certain situations. On the other hand, prescriptive norms characterise groups' moral norms and the perception about what most people approve or disapprove of, while not describing necessarily what happens in reality (Cialdini 1993; Deutsch and Gerard 1955). Basically, descriptive and prescriptive norms refer to the distinction between what is more often observed and what people would like to be more often observed (Costa-Lopes and Pereira 2012).

While meritocracy is seen as a social norm more typical of an Anglo Saxon society like the us, it is nonetheless something that is, to some extent, also conveyed in more collectivist societies like Portugal (Green, Deschamps and Páez 2005). Indeed, in Portugal, despite the belief in the importance of factors that are not related with merit, success is at least partially attributed to the personal merit of each individual. The sports' area is definitely the best source of examples acknowledging the importance of effort and hard work in obtaining success. Cristiano Ronaldo, for example, is often portrayed as someone who worked his way up the top of the football world. José Mourinho, one of the most famous and successful football coaches in the world, took 
part in an advertising campaign for a Portuguese bank in 2011. He would appear on large posters saying things like "I don't believe in luck, I believe in a job well done" or "Our work, our passion". This is just an example of the ever more prevalent norm of meritocracy that characterises most modern Western societies.

The rising presence of meritocracy in our society implies the need to study its effects. And, while meritocracy may be seen as an important and useful norm, - one that defines a fair criterion for the distribution of resources, - the fact is that this norm has been associated with higher justifications and stronger acceptance of inequality (Furnham 1982; McCoy and Major 2007) and also to more negative attitudes towards low status groups, both at the explicit (Vala, Lima and Lopes 2004) and the implicit level (Costa-Lopes, Wigboldus and Vala 2017). Despite these results, the study of socially critical decisions has, so far, neglected the role that a meritocratic norm may play in this area.

When people assume or believe that social status is a reflection of one's own merit or individual effort (i.e. when people endorse a descriptive meritocracy), one can make the individual "accountable" for the status that individual has, and therefore, meritocracy legitimises the status differences between individuals and between groups and helps to justify the status quo (McCoy and Major 2007; see also Jost and Hunyady 2005). Thus, if hierarchical status is based on merit, a possible logical inference indicates that individuals with a higher social status are more talented, hard-working and valuable. Using the same logic, low status individuals will be seen as lacking in worth and as possessing several negative features. If indeed a descriptive meritocratic norm is salient, these low status individuals are no longer seen as victims of a discriminatory system but instead as individually responsible for the negative situation they are in. This argument is nonetheless fallacious, as it does not account for the structural discrimination present in our societies and may in turn lead to the discrimination of people with a low social status, given that people's "worth" is often a criterion that people use to make distinctions that form the basis of decision making processes. A more indirect path, but consistent with this former idea and with the results described previously, clarifies that this legitimised perception of one's status may increase levels of implicit prejudice towards these people, and an increased implicit prejudice should lead to more unfavourable SCD (as shown above).

As previously explained, we aim to introduce the impact of meritocracy in SCD research. Thus, several issues remain unsolved: does the salience of a 
descriptive meritocratic norm have an impact on SCD? If so, how does that impact occur? Finally, do different decisional contexts and different types of decisions (e.g. snapshot vs. deliberate decisions) imply different or the same mechanisms?

To address these lacunae, our team initiated a research programme directly addressing the role of meritocracy in socially critical decisions towards low status groups in the several decisional contexts mentioned above.

\section{RESEARCH FROM OUR TEAM ${ }^{2}$ : ON MORAL DILEMMAS}

The first line of work we initiated was within the moral dilemmas area. So far, we have conducted two experimental studies that, taken together, provide initial support for the idea that when a meritocratic norm is made salient, people find negative decisions towards low status group members more acceptable.

The first study was collected online through social networks and involved 206 voluntary participants ( $75 \%$ female and with ages from 18 to 57 years old). Participants were asked to take part in two, supposedly unrelated, studies. Those "two unrelated studies" were in fact two parts of this same first study. The first "study" served to manipulate the salience of meritocracy, through a Scrambled Sentence Task (adapt. from Srull and Wyer 1979). Participants were asked to transform 18 sets of 5 words into 18 logical 4-word sentences. In the meritocracy condition, 10 sentences conveyed messages related to meritocracy (e.g. "Lazy people are unsuccessful."; "No pain, no gain.") and 8 presented neutral content (e.g. "A calculator saves time"). In the neutral condition, all 18 sentences presented neutral content ( 8 of the sentences were the same neutral ones as used in the Meritocracy condition). This task is a classic social psychological research tool for priming concepts and ideas.

In the supposed second study (in reality, the second part of the study), people would express their opinions on the trolley dilemma, providing their views on accepting the socially critical decision. As detailed above, in the trolley dilemma, people are faced with the challenging situation of deciding whether to sacrifice one victim to save five lives or do nothing. In our version of the trolley dilemma, we add pictorial information about the potential victim to be sacrificed. Specifically, after describing the dilemma, we tell participants

2 The team is made up of the authors of the present chapter. 
that they can see a picture of the person on the side track further down. We then ask participants how acceptable they would consider the decision to pull the lever and kill that victim to save the other five on the main track. Half of the participants would respond to this after seeing a picture of a well-off man, while the other half would respond to the same question after seeing a picture of a homeless man (included here to represent a member of a low status group). Results from this first study were not as hypothesised. In fact, a main result indicated that the sacrifice of the high-status victim was seen as more acceptable. Moreover, making meritocracy salient did not make the sacrifice of the low status victim more acceptable. We elaborated a post-hoc explanation for these unexpected results. Drawing from previous research on the content of stereotypes conducted in the us (Fiske et al. 2012), we assumed that homeless people were truly seen as a low status group, i. e. a group seen as having low competence and low warmth. According to Fiske and colleagues (2012), when that is the case, the group elicits disgust. However, we considered the hypothesis that, for Portuguese, this group of homeless people was, in fact, seen as low competence, but high on warmth, and thus eliciting pity. And this pity was probably "in the way" of accepting their sacrifice.

In a second study, we included a different low status group. A group that pre-tests showed as being seen as definitely a low-competence and low-warmth group: drug addicts. Participants were 141 university students ( $75 \%$ female, and ages from 18 to 63 years old), enrolled in the laboratory in exchange for $5 €$ gift cards. Results from this second study were more encouraging. Despite still showing a very strong acceptance of the sacrifice of high status victims, results also showed that participants who were in an experimental condition, where a meritocratic norm was made salient, were also the participants who considered the sacrifice of drug addicts as more acceptable.

\section{RESEARCH FROM OUR TEAM: ON MEDICAL DECISIONS}

The second line of research we initiated was devoted to the study of medical decisions. In this research, we examined whether the salience of meritocracy influences decision making in medical scenarios. We examined the relationship between priming meritocracy and assigning transplant priority for both low and high status targets. Additionally, we explored whether varying the degree of perceived responsibility over the disease would influence decision making 
(Study 1), and whether under time pressure participants are more likely to make discriminatory decisions towards low status groups (Study 2).

Study 1 and Study 2 were conducted online, with respectively 78 ( $78 \%$ female, with 24 years old on average) and 93 ( $71 \%$ female, 23 years old on average) participants.

For both studies, we hypothesised that, on average, individuals primed with a meritocratic norm would assign a lower priority level (in a transplant scenario) to a low status individual (compared to a high status one). In study 1 , we hypothesised that priming meritocracy along with a high responsibility disease would be the condition where the decision would be more unfavourable towards the low status individual.

The study again employed a two-study ruse. Participants were told they were taking part in two separate studies, one on "Cognitive Performance" (where they would go through the Scrambled Sentence Task) and one on "Decision Making Processes". In the "second study", participants were told to imagine themselves as being invited to be part of an evaluation panel, with the mission of assigning priority to patients, who are already on the waiting list for a heart transplant. They were then told to evaluate the clinical cases of six patients on the waiting list, and asked for their opinion regarding the level of priority to be assigned to each patient. In reality, we were only interested in the third and six clinical cases. These were identical medical cases that varied only in the status of the person depicted (low vs. high status, i. e. Black vs. White patient).

Again, results from the first study were not in line with our hypotheses. Even though results showed that participants who had previously been primed with meritocratic beliefs, evaluated the target differently only when the responsibility for the disease was high, the assignment of priority went in the opposite direction. We expected that priming individuals with concepts relevant to meritocracy would influence decision making when assigning priority to low status, in that the low status target would be more likely to receive a lower priority level, than the high status. Our results showed that when the fictitious patient had the high responsibility disease, participants in the meritocracy condition, were significantly more likely to assign a higher priority to the low status target, than to the high status target; and participants in the control condition were more likely to assign a higher priority to the high status than the low status one. We attributed these results to a potential overcorrection for low status targets showing a positive bias towards low 
status during the decision making process. According to the literature on implicit attitudes (Fazio 1990; Wilson et al. 2000; Dovidio et al. 1997), when participants become aware of study intent (e.g. racial issue), if they have the opportunity and motivation to think beforehand about the consequences of their decisions (e.g. discrimination), their responses will be primarily based on explicit attitudes. In this study, participants had sufficient time (e.g. opportunity) and might have been motivated to control for prejudice, which may have led them to overcorrect their responses towards the low status target.

Nevertheless, when the opportunity is not permitted (e.g. due to time pressure) implicit attitudes are more influential (Fazio 1990; Wilson et al. 2000; Dovidio et al. 1997). Following up on this idea, in Study 2 we focused on the perceived high responsibility disease, and added a time pressure condition sought to examine the salience effect of meritocracy on the participants' decision towards low status groups with a perceived high responsibility disease. Replicating the previous paradigm, we hypothesised that under the salience of meritocracy, participants in the high pressure condition would be more likely to assign a lower priority level to a low status patient (compared to a high status target). Results indicate that participants in the high pressure condition were marginally more likely to assign a lower priority to a low status patient than a high status patient. In contrast, participants in the low pressure condition were more likely to assign a higher priority to a low status patient, although this difference did not reach statistical significance. More importantly, results also showed that these effects were qualified by the condition of meritocracy salience. Specifically, under high pressure, participants were significantly more likely to assign a lower priority to the low status patient than the high status one, and this bias was significantly stronger in the condition where meritocracy was made salient.

\section{SOME PRELIMINARY CONCLUSIONS}

\section{AND UNFAVOURABLE SCD AS A BARRIER TO INCLUSION}

While providing initial support to the main hypothesis that meritocracy is associated with more unfavourable decisions towards low status group members, this research programme is still at a very incipient stage. Not only do we need to start addressing the other two types of decisions (in the legal context and the shoot vs. not shoot decisions), but we must also consolidate 
our knowledge on the obtained effects, namely through the analysis of the underlying mechanisms.

Nevertheless, the results obtained so far allow us to ponder the potentially dangerous consequences of promoting a meritocratic norm. What these results already seem to indicate is that when people are made to believe that society is structured along meritocratic principles, they will make inferences about what people deserve according to their situation. They will tend to think that people who are in unfavourable conditions (i. e. low status groups) are in those circumstances of their own accord, as if they are solely responsible for their situation. This kind of inference takes the place of any alternative thinking that considers other determining (societal) factors for people's situations. Additionally, this line of thinking legitimises discriminatory decisions about issues involving low status group members.

A significant part of the meaning of inclusion is about equal treatment and equal opportunities. What the results of our own work and the results of the other studies described in this chapter show is that people from low status groups are treated differently, and this difference consistently means a more negative treatment. They are more likely to be shot in police encounters; they are more likely to be sacrificed if the situation calls for such an act; they are more likely to be prescribed the wrong treatment in a medical context and they are more likely to be targeted with harsher sentences. Moreover, these results also indicate that if discussions emerge about the existence of this discriminatory behaviour, the narratives that ensue are characterised by discrimination-legitimising discourses that place the responsibility of the situation on the targets of discrimination. Thus, this research aims to contribute to a more nuanced reflection about the situation of low status groups and how attitudes and behaviours may be contributing to a vicious cycle, where the discussion about causality and responsibility may be tainted from the start by discriminatory or fallacious assumptions. 


\section{RUI COSTA-LOPES}

Instituto de Ciências Sociais, Universidade de Lisboa

Av. Prof. Aníbal Bettencourt 9-1600-036 Lisboa, Portugal

rui.lopes@ics.ulisboa.pt

orcid.org/0000-0002-1509-6397

\section{ANA FILIPA MADEIRA}

Instituto de Ciências Sociais, Universidade de Lisboa

filipa.madeira@ics.ulisboa.pt

orcid.org/00oo-0003-4959-7947

MARIANA PIRES DE MIRANDA

Instituto de Ciências Sociais, Universidade de Lisboa

mariana.miranda@ics.ulisboa.pt

orcid.org/oooo-0003-4208-2967

\section{WILSON MOREIRA}

Faculdade de Psicologia, Universidade de Lisboa

wrmoreirask@hotmail.com

orcid.org/00oo-0002-6799-0526

\section{$\S$ REFERENCES}

BALDUS, D., et al. 1998. "Racial discrimination and the death penalty in the post-Furman era: an empirical and legal overview, with recent findings from Philadelphia". Cornell Law Review, LXXXIII: 1638-1770.

BEAN, M., et al. 2014. "Documenting nursing and medical students' stereotypes about Hispanic and American Indian patients". Journal of Health Disparities Research and Practice, vII (4): 14-22.

BLAIR, I., C. Judd, and K. Chapleau. 2004. "The influence of Afrocentric facial features in criminal sentencing". Psychological Science, XV (10): 674-679.

BLAIR, I., et al. 2013. "Assessment of biases against Latinos and African Americans among primary care providers and community members". American Journal of Public Health, CIII (1): 92-98.

BOGART, L., et al. 2001. "Factors influencing physicians' judgments of adherence and treatment decisions for patients with HIV disease". Medical Decision Making, XXI (1): 28-36.

BURGESS, D. J., et al. 2008. "Patient race and physicians' decisions to prescribe opioids for chronic low back pain". Social Science and Medicine, LXVII (11): 1852-1860.

BURGESS, D. J., et al. 2014. “The effect of cognitive load and patient race on physicians' decisions to prescribe opioids for chronic low back pain: a randomized trial". Pain Medicine, xv (6): 965-974. 
CALABRESE, S., et al. 2014. “The impact of patient race on clinical decisions related to prescribing HIV pre-exposure prophylaxis (PrEP): assumptions about sexual risk compensation and implications for access". AIDS and Behavior, XVIII (2): 226-240.

CARAvelis, C., T. Chiricos, and W. Bales. 2013. "Race, ethnicity, threat, and the designation of career offenders". Justice Quarterly, xxx (5): 869-894.

CIALdini, R. 1993. The Psychology of Influence. New York: William Morrow and Co.

CIKARA, M., et al. 2010. "On the wrong side of the trolley track: Neural correlates of relative social valuation”. Social Cognitive and Affective Neuroscience, v (4): 404-413.

COOPER, L., et al. 2012. "The associations of clinicians' implicit attitudes about race with medical visit communication and patient ratings of interpersonal care”. American Journal of Public Health, CII (5): 979-987.

CORRELL, J., et al. 2002. “The police officer's dilemma: Using ethnicity to disambiguate potentially threatening individuals". Journal of Personality and Social Psychology, LXxxiII (6): 1314-1329.

CORRELL, J., et al. 2007. "Across the thin blue line: police officers and racial bias in the decision to shoot". Journal of Personality and Social Psychology, XCII (6): 1006-1023.

COSTA-LOPES, R., C. R. Pereira. 2012. "A normatividade das atitudes e do comportamento social: uma introdução". In Normas, Atitudes e Comportamento Social, orgs. R. Costa-Lopes and C. R. Pereira. Lisbon: Imprensa de Ciências Sociais, 15-24.

costa-Lopes, R., D. Wigboldus, and J. Vala. 2017. Priming Meritocracy Increases Implicit Prejudice. Lisbon: Colecção Working Papers ICs.

CÔtÉ, S., P. Piff, and R. Willer. 2013. "For whom do the ends justify the means? Social class and utilitarian moral judgment". Journal of Personality and Social Psychology, CIV (3): 490-503 .

CUshman, F., L. Young, and M. Hauser. 2006. "The role of conscious reasoning and intuition in moral judgment testing three principles of harm". Psychological Science, XVII (12): 1082-1089 .

DEHON, E., et al. 2017. "A systematic review of the impact of physician implicit racial bias on clinical decision making". Academic Emergency Medicine, xxIV (8): 895-904.

DEUTsCH, M., H. Gerard. 1955. "A study of normative and informational social influences upon individual judgment". The Journal of Abnormal and Social Psychology, LI (3): 629$-636$.

Di CACCAVo, A., N. Fazal-Short, and T. Moss. 2000. "Primary care decision making in response to psychological complaints: The influence of patient race". Journal of Community and Applied Social Psychology, x (1): 63-67.

Dovidio, J., et al. 1997. "On the nature of prejudice: Automatic and controlled processes". Journal of Experimental Social Psychology, XxxIII (5): 510-540.

Dovidio, J., S. Fiske. 2012. "Under the radar: how unexamined biases in decision-making processes in clinical interactions can contribute to health care disparities". American Journal of Public Health, CII (5): 945-952.

DRWECKI, B. B. 2011. "An experimental investigation of the causes of and solutions to racial pain treatment bias". Doctoral dissertation, Madison, University of Wisconsin-Madison.

EBERHARDT, J., et al. 2004. "Seeing black: Race, crime, and visual processing". Journal of Personality and Social Psychology, LXxxviI (6): 876-893.

FAIGMAN, D. L., et al. 2012. "Implicit Bias in the Courtroom". 59 UCLA Law Review, 1124: 1126$-1186$. 
FAZIO, R. 1990. "Multiple processes by which attitudes guide behavior: The MODE model as an integrative framework". In Advances in Experimental Social Psychology, ed. M. P. Zanna. San Diego, CA: Academic Press, 75-109.

FItzGERALD, C., and S. Hurst. 2017. "Implicit bias in healthcare professionals: A systematic review”. вMC Medical Ethics, XVIII (1): 19.

FURnham, A. 1982. "The Protestant work ethic and attitudes towards unemployment”. Journal of Occupational Psychology, LV (4): 277-285.

GRAHAM, S., and B. Lowery. 2004. "Priming unconscious racial stereotypes about adolescent offenders". Law and Human Behaviour, XXVIII (5): 483-504.

GREEN, A., et al. 2007. "Implicit bias among physicians and its prediction of thrombolysis decisions for black and white patients". Journal of General Internal Medicine, XxII (9): 1231-1238.

Green, E., J.-C. Deschamps, and D. Páez. 2005. "Variation of individualism and collectivism within and between 20 countries: a typological analysis". Journal of Cross-Cultural Psychology, XXXVI (3): 321-339.

GREENE, J., et al. 2001. "An fMRI investigation of emotional engagement in moral judgment". Science, CCXCIII (5537): 2105-2108.

HAIDER, A., et al. 2011. "Association of unconscious race and social class bias with vignettebased clinical assessments by medical students". Jama, CCCVI (9): 942-951.

HAIDER, A., et al. 2015a. "Unconscious race and social class bias among acute care surgical clinicians and clinical treatment decisions". JAMA Surgery, CL (5): 457-464.

HAIDER, A., et al. 2015 b. "Unconscious race and class biases among registered nurses: vignettebased study using implicit association testing". Journal of the American College of Surgeons, $\operatorname{CCXx}(6)$ : 1077-1086.

HALL, W., et al. 2015. "Implicit racial/ethnic bias among health care professionals and its influence on health care outcomes: a systematic review". American Journal of Public Health, CV (12): e60-e76.

HAUSMANN, L., et al. 2015. "Examining implicit bias of physicians who care for individuals with spinal cord injury: A pilot study and future directions". The Journal of Spinal Cord Medicine, XxxVIII (1): 102-110.

HenriQues, J. 2017. “A justiça em Portugal é 'mais dura' para os negros”. Público, Aug. 19, Revista. HIRsh, A., M. Jensen, and M. Robinson. 2010. "Evaluation of nurses' self-insight into their pain assessment treatment decisions". The Journal of Pain, XI (5): 454-461.

JOsT, J., O. Hunyady. 2005. "Antecedents and consequences of system-justifying ideologies". Current Directions in Psychological Science, XIV (5): 260-265.

KANT, I. 1959. Foundation of the Metaphysics of Morals. Indianapolis, IN: Bobbs-Merrill.

KLuegel, J., E. Smith. 1986. Beliefs About Inequality: Americans' View Of What Is And What Ought To Be. New Jersey: Aldine Transaction.

MAzzella, R., A. Feingold. 1994. "The effects of physical attractiveness, race, socioeconomic status, and gender of defendant and victims on judgments of mock jurors: A metaanalysis". Journal of Applied Social Psychology, XxIV (15): 1315-1338.

MCcoy, S., B. Major. 2007. "Priming meritocracy and the psychological justification of inequality". Journal of Experimental Social Psychology, XLIII (3): 341-351.

MILL, J. S. 1998. Utilitarianism. New York, NY: Oxford University Press.

MITCHELL, T., et al. 2005. "Racial bias in mock juror decision-making: a meta-analytic review of defendant treatment". Law and Human Behavior, XXIX (6): 621-637. 
moskowitz, G., J. Stone, and A. Childs. 2012. "Implicit stereotyping and medical decisions: unconscious stereotype activation in practitioners' thoughts about African Americans". American Journal of Public Health, CII (5): 996-1001.

NELLIS, A. 2016. "The color of justice: racial and ethnic disparity in state prisons". The Sentencing Project, http://www.sentencingproject.org/publications/color-of-justice-racia 1-and-ethnic-disparity-in-state-prisons/.

Oliveira, C., N. Gomes. 2014. Monitorizar A Integração de Imigrantes em Portugal: Relatório Estatístico Decenal. Lisbon: Alto Comissariado para as Migrações (ACM, IP).

Paradies, Y., M. Truong, and N. Priest. 2014. "A systematic review of the extent and measurement of healthcare provider racism". Journal of General Internal Medicine, XXIx (2): 364-387.

PAYNE, K. 2001. "Prejudice and perception: The role of automatic and controlled processes in misperceiving a weapon". Journal of Personality and Social Psychology, LXXXI (2): 181$-192$.

ponterotto, J., J. Potere, and S. Johansen. 2002. “The Quick Discrimination Index: Normative data and user guidelines for counseling researchers". Journal of Multicultural Counseling and Development, $\mathrm{xxx}(3): 192-207$.

RADELET, M. L., and Pierce, G. L. (1985). "Race and prosecutorial discretion in homicide cases”. Law and Society Review, 19: 587-621.

ROLDÃO, C. 2016. “Os afrodescendentes no sistema educativo português”. Paper presented at Encontros Mensais sobre Experiências Migratórias, Lisboa, Faculdade de Letras da Universidade de Lisboa, April 27.

SABIN, J., F. Rivara, and A. Greenwald. 2008. "Physician implicit attitudes and stereotypes about race and quality of medical care". Medical Care, XLVI (7): 678-685.

SABIN, J., et al. 2009. "Physicians' implicit and explicit attitudes about race by MD race, ethnicity, and gender". Journal of Health Care for the Poor and Underserved, xx (3): 896--913.

SCHAA, K., et al. 2015. "Genetic counselors' implicit racial attitudes and their relationship to communication". Health Psychology, xxxiv (2): 111-119.

schulman, K., et al. 1999. "The effect of race and sex on physicians' recommendations for cardiac catheterization”. New England Journal of Medicine, CCCXL (8): 618-626.

SEABra, H., and T. Santos. 2006. Reclusos Estrangeiros em Portugal: Esteios de Uma Problematização. Lisbon: Alto Comissariado para a Migração e Minorias Étnicas.

sommers, S., P. Ellsworth. 2000. "Race in the courtroom: Perceptions of guilt and dispositional attributions". Personality and Social Psychology Bulletin, XxVI (11): 1367-1379.

SOMMERs, S., and P. Ellsworth. 2001. "White juror bias: An investigation of prejudice against Black defendants in the American courtroom". Psychology, Public Policy, and Law, viI (1): 201-229.

SRULL, T., R. Wyer. 1979. “The role of category accessibility in the interpretation of information about persons: Some determinants and implications". Journal of Personality and Social Psychology, XxxviI (10): 1660-1672.

Stepanikova, I. 2012. "Racial-Ethnic Biases, Time Pressure, and Medical Decisions”. Journal of Health and Social Behavior, 53 (3): 329-343.

SwEEney, L., C. Haney. 1992. "The influence of race on sentencing: A meta-analytic review of experimental studies". Behavioral Sciences and the Law, x (2): 179-195.

THAMER, M., et al. 2001. "U. S. Nephrologists' attitudes towards renal transplantation: results from a national survey". Transplantation, LXXI (2): 281-288. 
VALA, J., M. Lima, and D. Lopes. 2004. "Social values, prejudice and solidarity in the European Union". In European Values at the End of the Millennium, eds. W. Arts, and L. Halman. Leiden: Brill.

VAN RYN, M., et al. 2006. "Physicians' perceptions of patients' social and behavioral characteristics and race disparities in treatment recommendations for men with coronary artery disease". American Journal of Public Health, XCVI (2): 351-357.

wilson, T., S. Lindsey, and T. Schooler. 2000. "A model of dual attitudes". Psychological Review, CVII: 101-126. eds. S. Aboim, P. Granjo, A. Ramos. Lisbon: Imprensa de Ciências Sociais, 137-158.

https://doi.org/10.31447/ics9789726715030.06 